\title{
The endothelial cell receptor GRP78 is required for mucormycosis pathogenesis in diabetic mice
}

\author{
Mingfu Liu, ${ }^{1}$ Brad Spellberg, ${ }^{2,3}$ Quynh T. Phan, ${ }^{1}$ Yue Fu, ${ }^{1,3}$ Yong Fu, 4 \\ Amy S. Lee, ${ }^{4}$ John E. Edwards Jr., ${ }^{1,3}$ Scott G. Filler,1,3 and Ashraf S. Ibrahim ${ }^{1,3}$

\begin{abstract}
${ }^{1}$ Division of Infectious Diseases, Los Angeles Biomedical Research Institute at Harbor-UCLA Medical Center, and ${ }^{2}$ Division of General Internal Medicine, Harbor-UCLA Medical Center, Torrance, California, USA. ${ }^{3}$ David Geffen School of Medicine at UCLA, Los Angeles, California, USA.
\end{abstract} \\ ${ }^{4}$ Norris Comprehensive Cancer Center, University of Southern California Keck School of Medicine, Los Angeles, California, USA.
}

\begin{abstract}
Mucormycosis is a fungal infection of the sinuses, brain, or lungs that causes a mortality rate of at least $50 \%$ despite first-line therapy. Because angioinvasion is a hallmark of mucormycosis infections, we sought to define the endothelial cell receptor(s) for fungi of the order Mucorales (the fungi that cause mucormycosis). Furthermore, since patients with elevated available serum iron, including those with diabetic ketoacidosis (DKA), are uniquely susceptible to mucormycosis, we sought to define the role of iron and glucose in regulating the expression of such a receptor. Here, we have identified glucose-regulated protein 78 (GRP78) as what we believe to be a novel host receptor that mediates invasion and damage of human endothelial cells by Rhizopus oryzae, the most common etiologic species of Mucorales, but not Candida albicans or Aspergillus fumigatus. Elevated concentrations of glucose and iron, consistent with those seen during DKA, enhanced GRP78 expression and the resulting $R$. oryzae invasion and damage of endothelial cells in a receptor-dependent manner. Mice with DKA, which have enhanced susceptibility to mucormycosis, exhibited increased expression of GRP78 in sinus, lungs, and brain compared with normal mice. Finally, GRP78-specific immune serum protected mice with DKA from mucormycosis. These results suggest a unique susceptibility of patients with DKA to mucormycosis and provide a foundation for the development of new therapeutic interventions for these deadly infections.
\end{abstract}

\section{Introduction}

Mucormycosis is a life-threatening infection caused by fungi of the order Mucorales, the most common etiologic species of which is Rhizopus oryzae. The most common predisposing risk factor for mucormycosis is diabetes mellitus, and it has been long established that patients with diabetic ketoacidosis (DKA) have a unique predisposition to this infection $(1,2)$. Unfortunately, despite surgical debridement and first-line antifungal therapy, the overall mortality of mucormycosis remains unacceptably high, and survivors are typically left with considerable disfigurement from the infection and surgery $(2,3)$. Clearly, new therapeutic strategies are needed for this deadly disease.

A hallmark of mucormycosis is the presence of extensive angioinvasion with resultant vessel thrombosis and tissue necrosis $(1,2)$. Ischemic necrosis of infected tissues can prevent delivery of leukocytes and antifungal agents to the foci of infection. Thus, angioinvasion is a key factor in the pathogenesis of mucormycosis. During angioinvasion, the organism invades and damages vascular endothelial cells. Therefore, understanding the mechanisms by which these processes occur may lead to new approaches to prevent and/or treat mucormycosis.

We have found that $R$. oryzae strains adhere to human umbilical vein endothelial cells in vitro and invade these cells by induced endocytosis (4). Endocytosed R. oryzae damages endothelial cells, and prevention of endocytosis abrogates the ability of the organisms to cause endothelial cell damage (4). In the current study, we sought to define a receptor responsible for $R$. oryzae adherence to

Conflict of interest: The authors have declared that no conflict of interest exists. Citation for this article: J Clin Invest. 2010;120(6):1914-1924. doi:10.1172/JCI42164. and invasion through endothelial cells and to determine whether glucose and iron levels consistent with those seen during DKA regulate the expression of such a receptor.

\section{Results}

GRP78 binds to Mucorales germlings but not spores. Because R. oryzae is likely to interact with endothelial cells in the germling form during angioinvasion (4), we used the affinity purification process developed by Isberg and Leong (5) to identify an endothelial cell receptor for $R$ oryzae germlings. When incubated with extracts of endothelial cell membrane proteins, $R$. oryzae bound to a major band at $78 \mathrm{kDa}$. Lesser and inconsistent binding was found to a band at approximately $70 \mathrm{kDa}$ and bands between $100-150 \mathrm{kDa}$ (Figure 1A).

The major band at $78 \mathrm{kDa}$ that bound to germlings was excised for protein identification by matrix-assisted laser desorption/ionization-time-of-flight tandem mass spectrometry (MALDI-TOF MS/ MS) analysis. Several potential matches were identified, including human glucose-regulated protein 78 (GRP78). Because of our interest on focusing on receptors whose expression is likely to be regulated in DKA, we selected GRP78 for further investigation. To verify that endothelial cell GRP78 bound $R$. oryzae germlings, we probed immunoblots containing endothelial cell membrane proteins with an anti-GRP78 polyclonal Ab raised against a synthetic peptide corresponding to amino acids 24-43 of human GRP78. This polyclonal Ab recognized the germlingbound $78-\mathrm{kDa}$ band (Figure 1B). Time course studies revealed that GRP78 was bound by germlings after $1-3$ hours of germination but not by R. oryzae spores (Figure 1C). Finally, endothelial cell GRP78 bound to germlings of other Mucorales family members that are known to cause mucormycosis, including another 
A

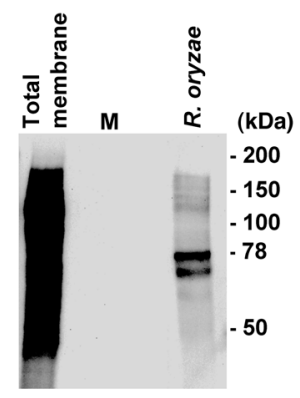

C

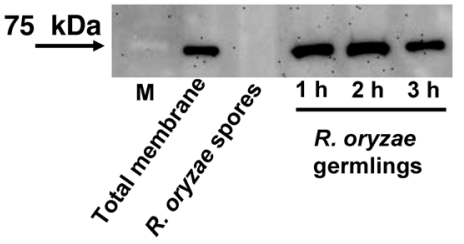

B

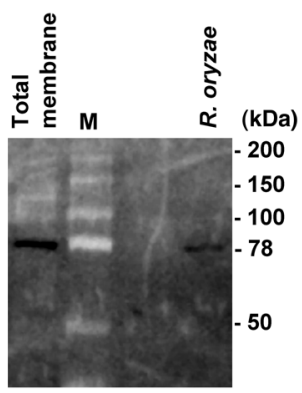

D

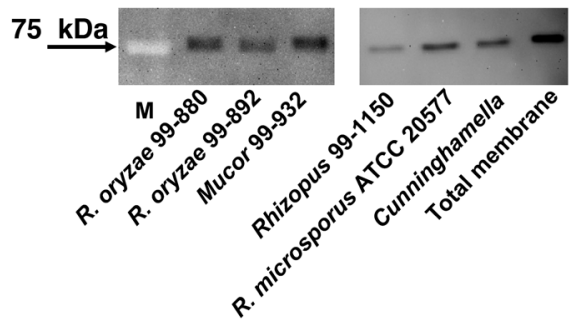

Figure 1

Endothelial cell surface GRP78 binds to Mucorales germlings. (A) Endothelial cell surface proteins were labeled with NHS-biotin (5) and then extracted with $n$-octyl- $\beta$-D-glucopyranoside in PBS containing $\mathrm{Ca}^{2+}$ and $\mathrm{Mg}^{2+}$ and protease inhibitors. The labeled proteins $(250 \mu \mathrm{g})$ were incubated with germlings $\left(2 \times 10^{8}\right)$ of $R$. oryzae, then the unbound proteins were removed by extensive rinsing with PBS containing $\mathrm{Ca}^{2+}$ and $\mathrm{Mg}^{2+}$. The membrane proteins that remained bound to the organisms were eluted with $6 \mathrm{M}$ urea, separated on $10 \%$ SDS-PAGE, and identified by immunoblotting with an anti-biotin monoclonal Ab. Proteins from another SDS-PAGE were stained with SYPRO Ruby and the bands excised for sequencing. (B) The same membrane that was probed with anti-biotin Ab was stripped and then probed with antiGRP78 Ab. (C) $R$. oryzae spores were germinated as previously described (4) for different time intervals, and binding to endothelial cell surface protein and immunoblotting against anti-GRP78 Ab were carried out as in A and B and compared with an equal volume of $R$. oryzae spores $\left(8 \times 10^{8}\right)$. (D) An immunoblot of endothelial cell surface proteins bound to different Mucorales was developed with an anti-GRP78 Ab. Total membrane, total endothelial cell membrane proteins; $\mathrm{M}$, molecular weight marker.

strain of R. oryzae, and strains of Rhizopus microsporus, Mucor species, and Cunninghamella species.

We next used indirect immunofluorescence to verify that GRP78 on intact endothelial cells was bound by R. oryzae. Endothelial cells expressed GRP78 on the cell surface (Figure 2, B and F), in accordance with previous reports $(6,7)$. When endothelial cells were infected with $R$. oryzae germlings, GRP78 colocalized with $R$. oryzae (Figure 2, D and H). These fungal cells were being endocytosed because they were surrounded by endothelial cell microfilaments (Figure 2, C and G). These findings confirm that during endocytosis, $R$. oryzae germlings bind to GRP78 on intact endothelial cells.

$G R P 78$ is a receptor for $R$. oryzae germlings. Because we previously showed that endocytosis of the fungus is a prerequisite for $R$. oryzae to cause endothelial cell damage (4), we sought to determine whether blocking the function or expression of GRP78 would protect endothelial cells from $R$. oryzae-induced endocytosis and subsequent damage. Endocytosis, but not adherence, of $R$. oryzae germlings was abrogated by addition of an anti-GRP78 but not control polyclonal $\mathrm{Ab}$, the latter of which targeted $\mathrm{p} 53$, which is not expressed by endothelial cells (Figure 3A). The anti-GRP78 Ab reduced by more than $40 \%$ damage to endothelial cells caused by R. oryzae germlings (Figure 3B) but not Candida albicans (Figure 3C) or Aspergillus fumigatus (Figure 3D).

To complement the Ab blocking studies, we sought to suppress GRP78 expression to determine its impact on adherence, endocytosis, and endothelial cell damage. Because GRP78 is essential (8), we employed shRNA to downregulate its expression. Transduction of endothelial cells with a lentivirus containing GRP78 shRNA mediated an $80 \%$ reduction in GRP78 transcript levels compared with endothelial cells transduced by non-target shRNA lentivirus (Figure 4A). This suppression of GRP78 expression resulted in a significant reduction in endothelial cell endocytosis of $R$. oryzae germlings and subsequent endothelial cell damage (Figure 4, B and C). Collectively, these results indicate that GRP78 is essential for maximal endocytosis of $R$. oryzae germlings by endothelial cells.

As an additional confirmatory method, we used the cell line C.1, which was derived from parental dihydrofolate reductase-deficient (DHFR-deficient) CHO cells engineered to overexpress hamster GRP78 $(9,10)$. C.1 cells overexpressed GRP78 transcript by 26 -fold compared with their parent cells (Figure 5A). The C. 1 cells had a $40 \%$ increase in endocytosis of $R$. oryzae germlings, which resulted in a more than 50\% increase in damage (Figure 5, B and $\mathrm{C}$ ) compared with the parent $\mathrm{CHO}$ cells, which do not overexpress GRP78. These results were specific to $R$. oryzae germlings, because CHO cells overexpressing GRP78 had no effect on endocytosis of $R$. oryzae spores, which do not bind GRP78 (data not shown). Thus, the enhanced endocytosis of germlings induced by GRP78 overexpression is not the result of a generalized increase in endocytosis. These results further support the concept that GRP78 functions as an endothelial cell receptor for $R$. oryzae germlings.

Iron regulates endothelial cell damage by $R$. oryzae. Patients with elevated available serum iron, such as DKA patients (11) or those treated with deferoxamine (an iron siderophore that provides Rhizopus with exogenous iron) (12), are uniquely predisposed to developing mucormycosis. Furthermore, the iron chelator deferasirox, which reduces available serum iron, is effective in treating experimental hematogenously disseminated mucormycosis (13). Given the role of iron in the pathogenesis of mucormycosis infections, we sought to define the impact of iron levels on endothelial cell endocytosis of $R$. oryzae. Endothelial cell adherence, endocytosis, and damage caused by $R$. oryzae were compared following exposure to phenanthroline (an iron chelator) with or without exogenous iron. As a positive control, $R$. oryzae germlings were incubated on endothelial cells that were exposed to the microfilament disruptant cytochalasin D, which prevents endocytosis (14). None of the treatments altered fungal adherence to endothelial cells (Figure 6A). However, similar to cytochalasin $\mathrm{D}$, phenanthroline reduced endothelial cell endocytosis of $R$. oryzae by approximately 70\% (Figure 6A). Further, the addition of exogenous iron completely reversed the inhibition of endocytosis caused by the iron chelator. Finally, phenanthroline prevented $R$. oryzae-induced endothelial cell damage in a concen- 
DIC
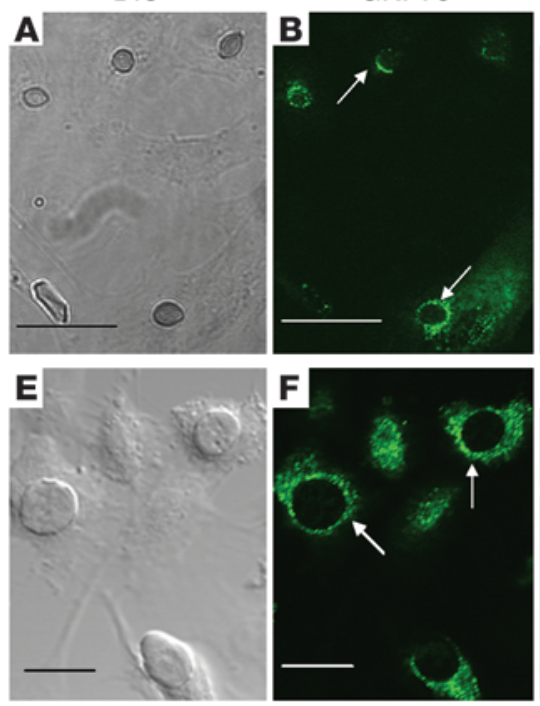

Actin
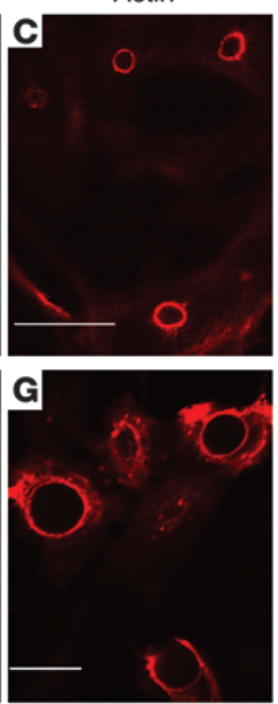

Overlay
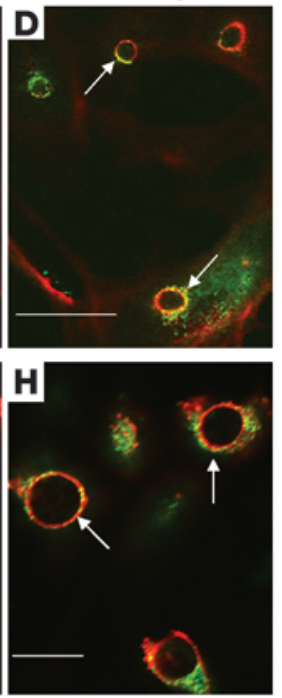

Figure 2

GRP78 on intact endothelial cells colocalizes with $R$. oryzae germlings that are being endocytosed. Confocal microscopic images of endothelial cells infected with $R$. oryzae cells that have been germinated for 1 hour $(\mathbf{A}-\mathbf{D})$ or 2 hours $(\mathbf{E}-\mathbf{H})$. Confluent endothelial cells on a $12-\mathrm{mm}$-diameter glass coverslip were infected with $105 / \mathrm{ml} R$. oryzae germlings. After 60 -minute incubation at $37^{\circ} \mathrm{C}$, the cells were fixed with $3 \%$ paraformaldehyde, washed, blocked, and then permeabilized (31). The cells were stained with GRP78 using rabbit anti-GRP78 polyclonal Ab (Abcam), followed by a counterstain with goat anti-rabbit IgG conjugated with Alexa Fluor 488 (Molecular Probes, Invitrogen) (B and F). To detect F-actin, the cells were incubated with Alexa Flour 568-labeled phalloidin (Molecular Probes) per the manufacturer's instructions ( $\mathbf{C}$ and $\mathbf{G})$. A merged image is shown in $\mathbf{D}$ and H. (A and E) The same fields taken with differential interference contrast imaging. Arrows indicate GRP78 and microfilaments that have accumulated around $R$. oryzae. Scale bars: $30 \mu \mathrm{m}(\mathbf{A}-\mathbf{D})$ and $20 \mu \mathrm{m}(\mathbf{E}-\mathbf{H})$.

tration-dependent manner (Figure 6B). Thus, iron regulates the susceptibility of endothelial cells to damage caused by $R$. oryzae by modulating endocytosis of the organism.

Iron and glucose are inducers of GRP78. Patients with DKA have elevated levels of available serum iron, likely due to release of iron from binding proteins in the presence of acidosis (11). We hypothesized that high iron and glucose concentrations similar to those seen in DKA patients induce expression of GRP78, thereby making the host more susceptible to mucormycosis. To test this hypothesis, we first confirmed that acidosis affects the expression of GRP78 through an iron-related mechanism. Endothelial cells were incubated at $\mathrm{pH}$ values similar to those seen in patients with DKA, and their GRP78 expression was quantified by real-time RT-PCR. Lower $\mathrm{pH}$ values significantly enhanced expression of endothelial cell GRP78 compared with the normal blood $\mathrm{pH}$ of 7.4 (Figure 7A). Furthermore, addition of the iron chelator phenanthroline in the setting of acidosis reversed GRP78 expression back to normal levels seen with $\mathrm{pH} 7.4$, indicating that the impact of acidosis is to release free iron from iron-binding proteins and that the increased free iron is the direct mediator of GRP78 expression.

To further study the role of iron and glucose directly on endothelial cell GRP78 expression, we incubated endothelial cells in increasing concentrations of $\mathrm{FeCl}_{3}$ and glucose for varying time intervals and quantified the level of GRP78 transcript by real-time RT-PCR. Endothelial cells incubated with concentrations of iron present in sera collected from patients with DKA (11) induced up to a 12-fold increase in endothelial cell GRP78 expression compared with endothelial cells incubated with no iron (Figure 7B). Similarly, incubating endothelial cells with glucose at 4 or $8 \mathrm{mg} / \mathrm{ml}$ led to a 3 - or 4 -fold increase in mRNA expression of GRP78, respectively, compared with cells incubated in a normal physiological concentration of glucose $(1 \mathrm{mg} / \mathrm{ml}$, $P=0.005)$ (Figure 7C). To discern whether GRP78 overexpression in response to glucose was due to hyperglycemia itself, or rather to hyperosmolarity caused by the increased glucose, we measured the expression of GRP78 after incubating endothelial cells with similar concentrations of mannitol (i.e., 1, 4, and $8 \mathrm{mg} / \mathrm{ml}$ ) for 20 hours. No change in GRP78 expression was noticed (data not shown), indicating that hyperglycemia and not hyperosmolarity is responsible for the enhanced GRP78 expression. Based on a previous hypothesis that HMG-CoA reductase inhibitors (i.e., statins) might affect mucormycosis incidence in diabetic patients (15), we also tested the impact of lovastatin on GRP78 expression and found no evidence of alterations in expression in the presence of the statin (data not shown).

To confirm that the increased mRNA expression of GRP78 translated into increased protein surface expression, we incubated endothelial cells with 0,15 , or $50 \mu \mathrm{M} \mathrm{FeCl}_{3}$, the latter of which mediated the strongest increase in mRNA transcription, and stained them with anti-GRP78 monoclonal Ab or isotype control. Fluorescence was quantified by flow cytometry. Surface expression of GRP78 protein increased by $150 \%$ in the presence of high iron levels (Figure 7D).

Iron-and glucose-induced GRP78 overexpression enhances susceptibility of endothelial cells to $R$. oryzae-induced invasion and damage. Incubation of endothelial cells with either 15 or $50 \mu \mathrm{M} \mathrm{FeCl}_{3}$ enhanced $R$. oryzaeinduced endocytosis and subsequent damage by $80 \%$ compared with endothelial cells incubated without exogenous $\mathrm{FeCl}_{3}$ (Figure 8A). Similarly, incubation of endothelial cells with $4-8 \mathrm{mg} / \mathrm{ml}$ glucose resulted in approximately $20 \%$ and $40 \%$ increases in endocytosis of and damage caused by $R$. oryzae, respectively, when compared with endothelial cells incubated in $1 \mathrm{mg} / \mathrm{ml}$ glucose (Figure $8 \mathrm{~B}$ ). Importantly, the anti-GRP78 Ab blocked this enhanced endothelial cell susceptibility to $R$. oryzae-induced damage, confirming the specificity of the increased susceptibility to overexpression of GRP78 (Figure 9). Collectively, these results confirm that iron and glucose concentrations consistent with those seen in patients with DKA induce the overexpression of GRP78, resulting in enhanced endocytosis and damage of endothelial cells.

GRP78 during mucormycosis in vivo. To determine the potential role for GRP78 in mediating susceptibility to mucormycosis in vivo, we quantified Grp78 expression by RT-PCR in mice with DKA (which, like humans, are hypersusceptible to mucormycosis) (16) and in normal mice. Mice were rendered diabetic with streptozotocin $(16,17)$. Diabetes was confirmed by measurement of increased urinary glucose levels. Concordant with the establishment of DKA, diabetic mice had a decrease in blood $\mathrm{pH}$ from 
A

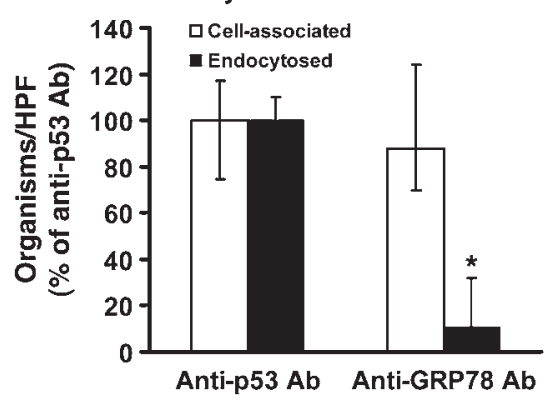

C
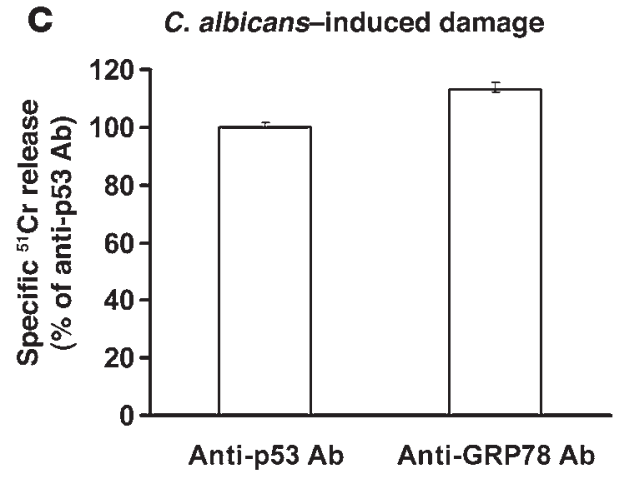

B

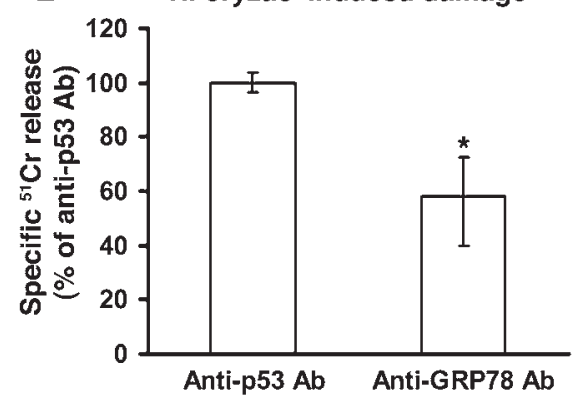

D A. fumigatus-induced damage

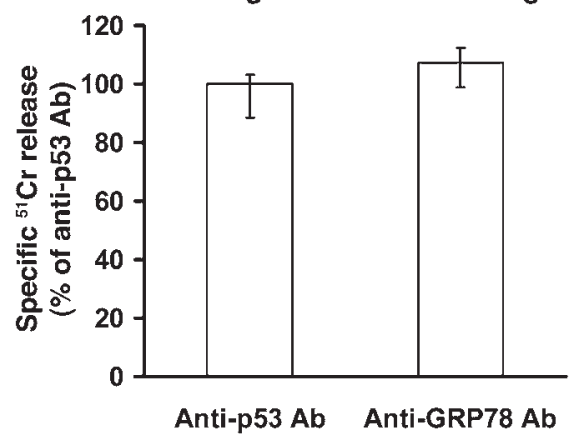

Figure 3

Anti-GRP78 Ab blocks endothelial cell endocytosis of and damage by $R$. oryzae but not damage caused by $C$. albicans or $A$. fumigatus. Adherence and endocytosis (determined by differential fluorescence) assays were carried out using endothelial cells split on 12-mm glass coverslips, while damage was carried out using the 96 -well plate ${ }^{51} \mathrm{Cr}$ release method. Endothelial cells were incubated with $50 \mu \mathrm{g} / \mathrm{ml}$ anti-GRP78 or anti-p53 Ab (control) (Santa Cruz Biotechnology Inc.) for 1 hour prior to addition of $R$. oryzae germlings. Blocking of GRP78 with Ab abrogates endocytosis of $R$. oryzae by endothelial cells (data derived from $>700$ fungal cells interacting with approximately 200 endothelial cells/each group/experiment, with an average of $59 \%$ cells being endocytosed in the control) (A) and reduces the ability of the fungus to cause endothelial cell damage (B). However, anti-GRP78 Ab did not block damage caused by $C$. albicans (C) or $A$. fumigatus (D). ${ }^{*} P<0.01$ compared with anti-p53 Ab by Wilcoxon rank-sum test. $n=6$ slides per group from 3 independent experiments for endocytosis, and $n=6$ wells per group from 2 independent experiments for damage assay. Data are expressed as median \pm interquartile range.

7.8 (normal for mice) to 7.3-7.2, associated with increased levels of urinary glucose $(250-1,000 \mathrm{mg} / \mathrm{dl})$ and urinary ketone bodies $(\geq 5 \mathrm{mg} / \mathrm{dl})$ as determined by Keto-Diastix strip testing. We also compared levels of serum-free iron (i.e., unbound by carrier proteins such as transferrin) in DKA mice with those in normal mice. In accordance with the results found in humans (11), DKA mice $(n=11)$ had approximately 5 -fold-higher levels of serumfree iron than normal mice (median [25th quartile, 75 th quartile], $7.29[4.3,11.8] \mu \mathrm{M}$ vs. $1.69[1.3,2.3] \mu \mathrm{M} ; P=0.03$ by Wilcoxon rank-sum test). Finally, concordant with the regulation of GRP78 expression by iron and glucose levels, DKA mice were found to express 2- to 5-fold-higher levels of Grp78 mRNA in sinus, lungs, and brain compared with normal mice (Figure 10A).

To determine the potential for abrogation of GRP78 function as a treatment for mucormycosis, we vaccinated female BALB/c mice with recombinant hamster GRP78 (which is more than $98 \%$ identical to murine or human GRP78), and serum was collected from GRP78-immunized or control mice. The median anti-GRP78 $\mathrm{Ab}$ titer of serum collected from vaccinated mice was found to be $1: 128,000$ compared with a titer of 1:600 in the serum collected from mice vaccinated with adjuvant alone as determined by ELISA mucormycosis are acidotic $(18,20)$

Therefore, diabetes is a risk for mucormycosis even in the absence of acidosis, but acidosis enhances the predisposition of diabetic patients to mucormycosis. The causes of this predisposition of patients with diabetes, and DKA in particular, to mucormycosis has never been adequately explained.

Our results greatly elucidate the predisposition of diabetic and DKA patients to mucormycosis. We found that GRP78 expression was enhanced in hosts with elevated available serum iron levels and high glucose concentrations, and this enhanced expression of GRP78 resulted in increased endocytosis of $R$. oryzae by human endothelial cells and subsequent enhanced damage to the cells. Furthermore, suppression of GRP78 function by $\mathrm{Ab}$ and its reduced expression levels by shRNA blocked $R$. oryzae uptake and resulting damage to human endothelial cells. In contrast, the anti-GRP78 Abs did not block fungal endothelial cell damage mediated by C. albicans or A. fumigatus, two other fungal pathogens that do not have an increased attack rate in patients with DKA. Most importantly, our results clearly showed that mice with DKA, which had elevated levels of glucose and available iron and overexpressed Grp78 in relevant target tissues, were protected from mucormycosis infection when the recep- 
A

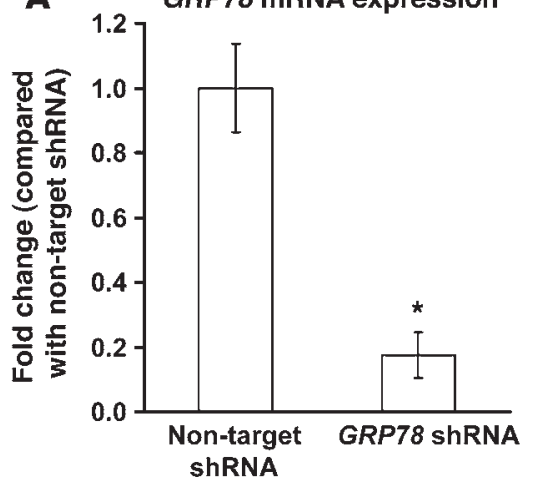

B

Endocytosis and adherence

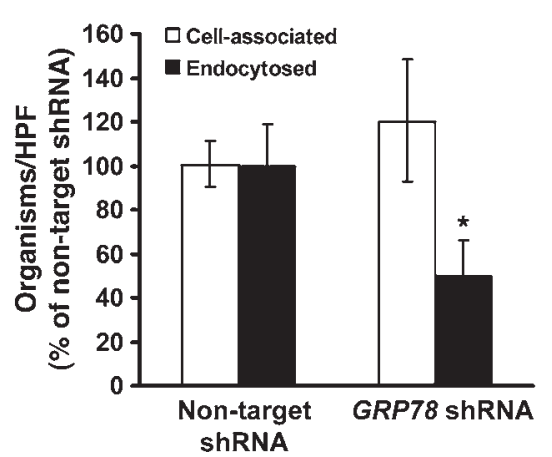

C

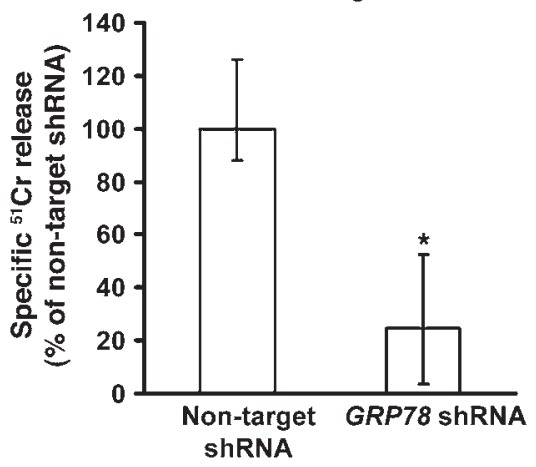

Figure 4

Downregulation of endothelial cell GRP78 expression with shRNA reduces the number of endocytosed organisms and subsequent damage to endothelial cells. Endothelial cells were transduced with lentivirus containing either shRNA targeting GRP78 or a scrambled sequence (Non-target shRNA). Transduction of endothelial cells with GRP78 shRNA lentiviruses reduced GRP78 transcript levels (A), diminished the number of endocytosed $R$. oryzae germlings (data derived from $>800$ fungal cells interacting with approximately 250 endothelial cells/each group/experiment, with an average of $76 \%$ being endocytosed in the non-target shRNA) (B), and blocked $R$. oryzae-induced endothelial cell damage $(\mathbf{C}) .{ }^{*} P<0.005$ compared with non-target shRNA by Wilcoxon rank-sum test for all comparisons. $n=6$ slides per group from 3 independent experiments for endocytosis, and $n=6$ wells per group from 2 independent experiments for damage assay. Data are expressed as median \pm interquartile range.

tor was blocked by Abs. These exciting results underscore the therapeutic potential of GRP78-blocking strategies in treating or preventing mucormycosis.

Exposure to hyperglycemia of iron-sequestering proteins, such as apotransferrin and hemoglobin, has been shown to damage the proteins and cause them to release free iron in $\operatorname{serum}(21,22)$. Therefore, diabetes can result in increased serum-free iron even in the absence of acidosis. Furthermore, acidosis has been shown to markedly increase dissociation of iron from sequestering proteins in serum from DKA patients, independent of glucose levels (11). Our data confirm that hyperglycemia as well as increased iron levels in the absence of hyperglycemia increase expression of GRP78 in host cells. Thus, increased GRP78 expression caused by hyperglycemia can explain the predisposition of non-acidotic diabetic patients to mucormycosis, whereas the potentiation of increased free iron levels caused by acidosis explains the marked increase in attack rate of mucormycosis in patients with DKA.

GRP78 (also known as BiP/HSPA5) was discovered as a cellular protein induced by glucose starvation (23). It is a member of the HSP70 protein family that is mainly present in the endoplasmic reticulum. It functions as a major chaperone that is involved in many cellular processes, including protein folding and assembly, marking misfolded proteins for proteosome degradation (24), regulating $\mathrm{Ca}^{2+}$ homeostasis, and serving as a sensor for endoplasmic reticulum stress (6).
A

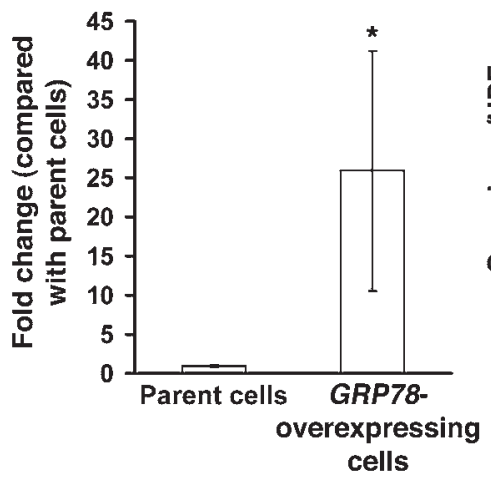

B

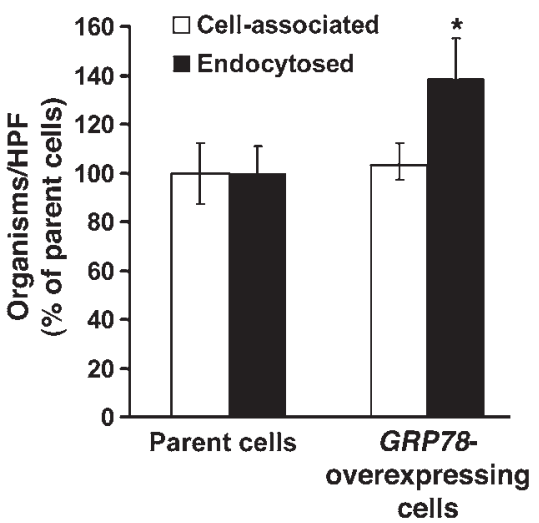

C

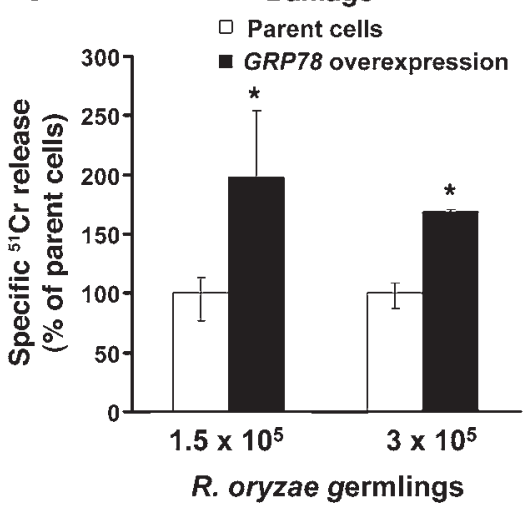

Figure 5

Heterologous overexpression of GRP78 in $\mathrm{CHO}$ cells makes them more susceptible to R. oryzae-induced invasion and subsequent damage. The C.1 cell line, which was derived from parental DHFR-deficient $\mathrm{CHO}$ cells engineered to overexpress GRP78, was found to overexpress GRP78 (A). ${ }^{*} P=0.01$ compared with parent cells by nonparametric Wilcoxon rank-sum test; $n=6$ per each group. C. 1 cells were able to endocytose more $R$. oryzae germlings (data derived from $>950$ fungal cells interacting with approximately $300 \mathrm{CHO}$ cells/each group/experiment, with an average of $40.9 \%$ being endocytosed in the parent cells) (B) and were more susceptible to $R$. oryzae-induced damage (C). ${ }^{*} P<0.005$ compared with parent cells by Wilcoxon rank-sum test. $n=6$ slides per group from 3 independent experiments for endocytosis, and $n=6$ wells per group from 2 independent experiments for damage assay. Data are expressed as median \pm interquartile range. 

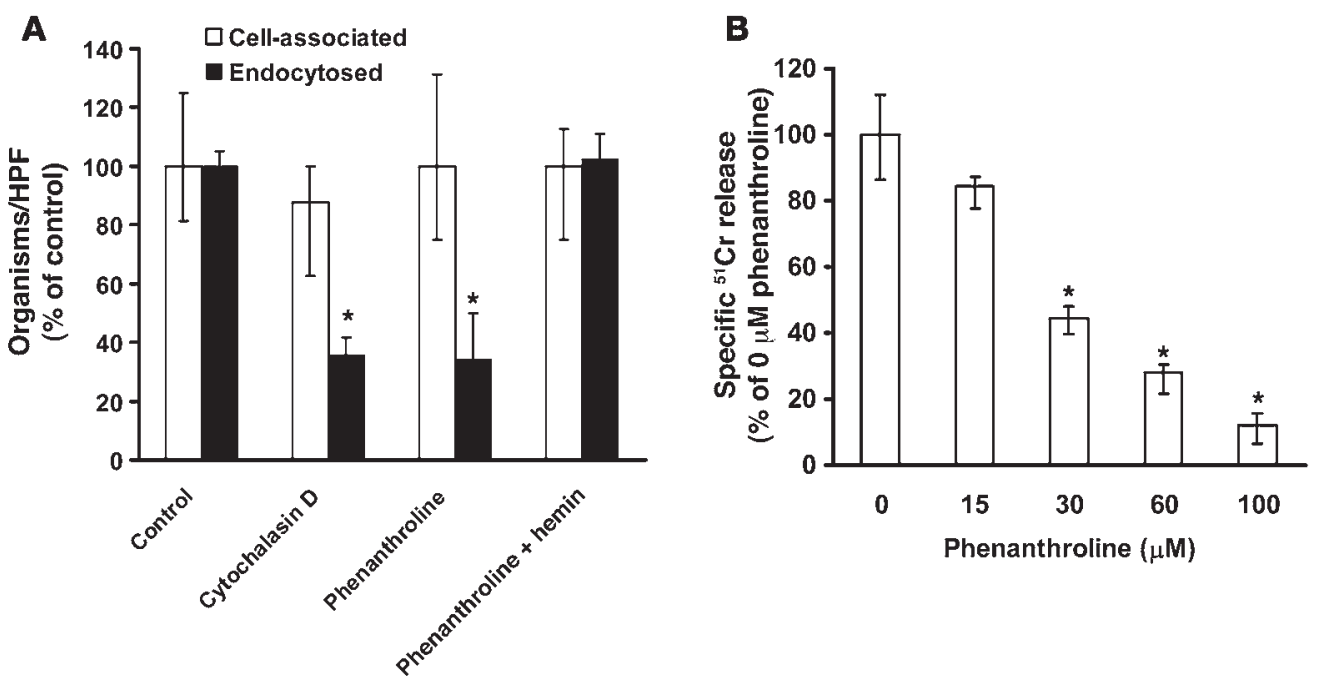

\section{Figure 6}

Chelation of endothelial cell iron protects the cells from invasion and subsequent damage by R. oryzae. (A) Endothelial cells were incubated with the iron chelator phenanthroline $(60 \mu \mathrm{M})$, cytochalasin $\mathrm{D}(200 \mathrm{nM})$, or phenanthroline saturated with hemin $(20 \mu \mathrm{M})$ for 16 hours, then the cells were rinsed and processed for endocytosis and adherence (data derived from $>400$ fungal cells interacting with approximately 150 endothelial cells/each group/experiment, with an average of $77 \%$ being endocytosed in the control). (B) Endothelial cells were treated with varying concentrations of phenanthroline for 16 hours, then the iron chelator was removed prior to carrying out $R$. oryzae-induced endothelial cell damage. ${ }^{*} P<0.001$ versus control ( $R$. oryzae germlings without phenanthroline) by Wilcoxon rank-sum test. $n=6$ slides per group from 3 independent experiments for endocytosis, and $n=8$ wells per group from 2 independent experiments for damage assay. Data are expressed as median \pm interquartile range.

GRP78 has also been reported to be antiapoptotic and plays critical cytoprotective roles in early embryogenesis, oncogenesis, neurodegenerative diseases, and atherosclerosis (23). More recently, GRP78 overexpression was shown to inhibit both insulin-dependent and endoplasmic reticulum stress-induced SREBP-1 activation, resulting in reduction of hepatic steatosis in obese mice (25).

Despite its main function as a cellular chaperone protein, recent studies reported the translocation of a fraction of GRP78 to the cell surface in a variety of cells (26). In fact, GRP78 has been reported to function as a receptor for a variety of ligands, including (a) the angiogenesis inhibitor Kringle 5 (7), (b) the activated proteinase inhibitor $\alpha 2$-macroglobulin (27), (c) a synthetic 12-aa peptide (28), (d) dengue virus serotype 2 (29), and (e) a coreceptor for Coxsackievirus A9 (30). To our knowledge, this is the first report that GRP78 acts as a receptor for fungal pathogens. We found that GRP78 acts as a receptor for invasion but not adherence of Mucorales to endothelial cells. Similarly, $\mathrm{N}$-cadherin was shown to mediate invasion but not adherence of C. albicans to endothelial cells (31), demonstrating that adherence and invasion are two independent processes mediated by different receptors. The fungal ligand for GRP78 that mediates invasion of endothelial cells is under active investigation.

With regard to the effect of iron on GRP78, previous work demonstrated paradoxical effects of iron on GRP78 expression in animal models. For example, mRNA and protein levels of GRP78 were decreased in iron-fed C57BL/ 6 mice, while they were unchanged in iron-fed $129 / \mathrm{Sv}$ mice (32). In contrast, rats with chronic or acute iron overloaded had increased GRP78 expression in hearts and livers compared with control rats (33). We found iron to have a drastic effect on increasing the cell surface expression of GRP78. Higher glucose concentrations also increased expression of GRP78, but to a lesser extent. These results are in agreement with the findings of Mote et al., who reported that Chinese hamster lung fibroblasts expressed 30\% more GRP78 when cultured in medium with a glucose concentration of $4.5 \mathrm{mg} / \mathrm{ml}$ compared with medium with a glucose concentration of $1.5 \mathrm{mg} / \mathrm{ml}$ (34).

Our findings that DKA mice have elevated available serum iron and increased serum glucose, and expressed more Grp78 in their organs, underscore the physiological relevance of our in vitro findings. More importantly, we found that anti-GRP78 Ab protected DKA mice from $R$. oryzae infection. The mechanism of immunological protection is currently under investigation.

In summary, multiple independent lines of investigation demonstrate that GRP78 functions as a receptor for Mucorales that facilitates fungus-induced penetration and subsequent damage of endothelial cells. Additionally, expression of the receptor and subsequent invasion of and damage to endothelial cells in a receptor-dependent manner were increased in the presence of elevated concentrations of iron and glucose, consistent with those seen in patients with DKA. Most important, anti-GRP78 Ab protected DKA mice from infection with mucormycosis. These results provide insight into why patients with DKA are uniquely susceptible to mucormycosis infections and provide a foundation for therapeutic interventions against extremely lethal mucormycosis.

\section{Methods}

R. oryzae and culture conditions. Several clinical Mucorales isolates were used in this study. R. oryzae 99-880 and Mucor sp 99-932 are brain isolates, while R. oryzae 99-892 and Rhizopus sp 99-1150 were isolated from lungs of infected patients and obtained from the Fungus Testing Laboratory, University of Texas Health Science Center at San Antonio, San Antonio, Texas, USA. Cunninghamella bertholletiae 182 is also a clinical isolate and was a gift from Thomas Walsh (NIH, Bethesda, Maryland, USA). Rhizopus microsporus ATCC 20577 is an environmental isolate obtained from ATCC. A. fumigatus AF293 

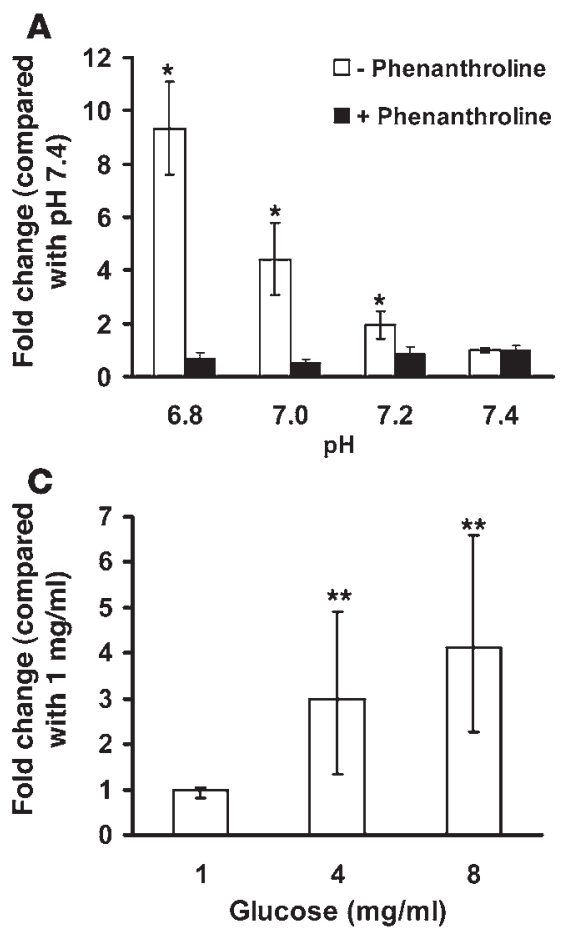

B

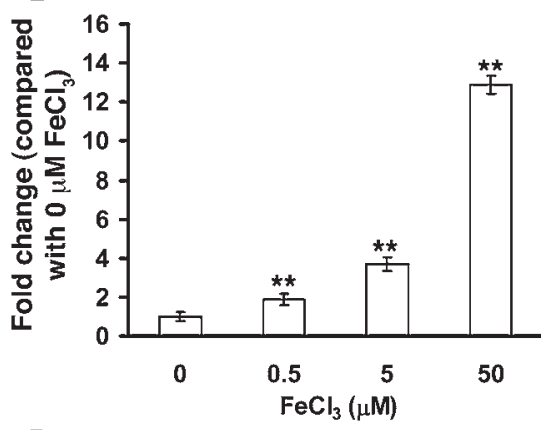

D

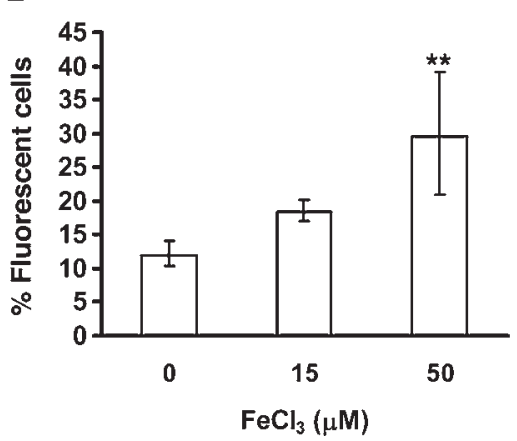

\section{Figure 7}

Acidosis as well as iron and glucose concentrations consistent with those seen in DKA patients induce expression of GRP78. Endothelial cells were incubated at various $\mathrm{pHs}$ with or without phenanthroline (A), with iron (B) or glucose (C) concentrations often seen in DKA patients for 5 hours (for studying the effect of acidosis or iron) or 20 hours (for studying the effect of glucose), then the expression of GRP78 was quantified by real-time RT-PCR. $n=6$ wells per group from 2 independent experiments. Data are expressed as median \pm interquartile range. Cell surface expression of GRP78 on endothelial cells ( $n=4$ per group from 2 independent experiments) exposed to $\mathrm{FeCl}_{3}$ was quantified using FACS analysis following staining with anti-GRP78 $\mathrm{mAb}$, then counterstaining with anti-mouse Alexa Fluor 488-labeled Ab (D). Data are presented as percent of median fluorescent cells \pm interquartile range. ${ }^{*} P<0.01$ versus $\mathrm{pH} 7.4$ or the same $\mathrm{pH}$ with phenanthroline; ${ }^{* *} P<0.05$ versus $1 \mathrm{mg} / \mathrm{ml}$ glucose or 0 $\mathrm{FeCl}_{3}$ by Wilcoxon rank-sum test. and C. albicans SC5314 are clinical isolates that were used to determine whether anti-GRP78 Ab blocks endothelial cell damage caused by these two organisms. Mucorales were grown on potato dextrose agar (PDA; BD Biosciences Diagnostic Systems) plates for $3-5$ days at $37^{\circ} \mathrm{C}$, while A. fumigatus and C. albicans were grown on Sabouraud dextrose agar (SDA) plates for 2 weeks and 48 hours, respectively, at $37^{\circ} \mathrm{C}$. The sporangiospores were collected in endotoxin-free Dulbecco's PBS containing $0.01 \%$ Tween 80 (for Mucorales) and $0.2 \%$ Tween 80 (for A. fumigatus), washed with PBS, and counted with a hemocytometer to prepare the final inocula. For C. albicans, blastospores were collected in PBS after the organisms were grown in YPD medium (1\% yeast extract [Difco Laboratories], 2\% Bacto Peptone [Difco Laboratories], and 2\% glucose [Sigma-Aldrich]) at $30^{\circ} \mathrm{C}$ overnight. To form germlings, spores were incubated in liquid YPD medium at $37^{\circ} \mathrm{C}$ with shaking for $1-3$ hours based on the assay under study. Germlings were washed twice with RPMI 1640 without glutamine (Irvine Scientific) for all assays used, except in experiments involving isolation of the endothelial cell receptor, for which the germlings were washed twice with PBS (plus $\mathrm{Ca}^{2+}$ and $\mathrm{Mg}^{2+}$ ).

Endothelial cells and $\mathrm{CHO}$ cells. Endothelial cells were collected from umbilical vein endothelial cells by the method of Jaffe et al. (35). The cells were harvested by using collagenase and were grown in M-199 (Gibco BRL) enriched with $10 \%$ fetal bovine serum, $10 \%$ defined bovine calf serum, L-glutamine, penicillin, and streptomycin (all from Gemini Bio-Products). Second-passage cells were grown to confluency in 96-well tissue culture plates (Costar) on fibronectin (BD Biosciences). All incubations were in $5 \% \mathrm{CO}_{2}$ at $37^{\circ} \mathrm{C}$. The reagents were tested for endotoxin using a chromogenic limulus amebocyte lysate assay (BioWhittaker Inc.), and the endotoxin concentrations were less than $0.01 \mathrm{IU} / \mathrm{ml}$. Endothelial cell collection was approved by the Institutional Review Board of Los Angeles Biomedical Research Institute at Harbor-UCLA Medical Center. CHO cell line C.1, which was derived from parental DHFRdeficient CHO cells engineered to overexpress GRP78s, was a gift of Randall Kaufman, University of Michigan, Ann Arbor, Michigan, USA $(9,10)$.

Extraction of endothelial cell membrane proteins. Endothelial cell membrane proteins were extracted according to the method of Isberg and Leong (5). Briefly, confluent endothelial cells in 100-mm-diameter tis- sue culture dishes were rinsed twice with warm Dulbecco's PBS containing $\mathrm{Ca}^{2+}$ and $\mathrm{Mg}^{2+}(\mathrm{PBS}-\mathrm{CM})$ and then incubated with EZ-Link SulfoNHS-LS-Biotin $(0.5 \mathrm{mg} / \mathrm{ml}$; Pierce $)$ in PBS-CM for 12 minutes at $37^{\circ} \mathrm{C}$ in $5 \% \mathrm{CO}_{2}$. The cells were then rinsed extensively with cold PBS-CM and scraped from the tissue culture dishes. The endothelial cells were collected by centrifugation at $500 \mathrm{~g}$ for 5 minutes at $4^{\circ} \mathrm{C}$ and then lysed by incubation for 20 minutes on ice in PBS-CM containing 5.8\% n-octyl$\beta$-D-glucopyranoside (w/v) (Calbiochem) and protease inhibitors ( $1 \mathrm{mM}$ phenylmethylsulfonyl fluoride, $1 \mu \mathrm{g} / \mathrm{ml}$ pepstatin A, $1 \mu \mathrm{g} / \mathrm{ml}$ leupeptin, and $1 \mu \mathrm{g} / \mathrm{ml}$ aprotinin) (Sigma-Aldrich). The cell debris was removed by centrifugation at $5,000 \mathrm{~g}$ for 5 minutes at $4^{\circ} \mathrm{C}$. The supernatant was collected and centrifuged at $100,000 \mathrm{~g}$ for 1 hour at $4^{\circ} \mathrm{C}$. The concentration of the endothelial cell proteins in the resulting supernatant was determined using the Bradford method (Bio-Rad).

Isolation of endothelial cell receptors that bind to Mucorales. Live Mucorales spores $\left(8 \times 10^{8}\right)$ or an equivalent volume of $1-3$ hour germlings (approximately $2 \times 10^{8}$ cells) were incubated for 1 hour on ice with $250 \mu \mathrm{g}$ of biotin-labeled endothelial cell surface proteins in PBS-CM plus $1.5 \% n$-octyl$\beta$-D-glucopyranoside and protease inhibitors. The unbound endothelial cell proteins were washed away by 3 rinses with this buffer. The endothelial cell proteins that remained bound to the fungal cells were eluted twice with $6 \mathrm{M}$ urea (Fluka), and the supernatant was combined and concentrated to an appropriate volume with a Microcon centrifugal filter $(10,000$ MWCO; Millipore). The proteins were then separated on 10\% SDS-PAGE and transferred to PVDF-plus membranes (GE Water \& Process Technologies). The membrane was then treated with Western Blocking Reagent (Roche) and probed with a mouse anti-biotin monoclonal Ab (SigmaAldrich). The membrane was then washed and incubated with secondary Ab, HRP-conjugated sheep anti-mouse IgG (Sigma-Aldrich). After incubation with SuperSignal West Dura Extended Duration Substrate (Pierce), the signals were detected using a CCD camera.

To identify endothelial cell proteins that bound to Mucorales, we incubated endothelial cell membrane proteins with $R$. oryzae germlings as above. The eluted proteins were separated by SDS-PAGE, and the gel was 
A

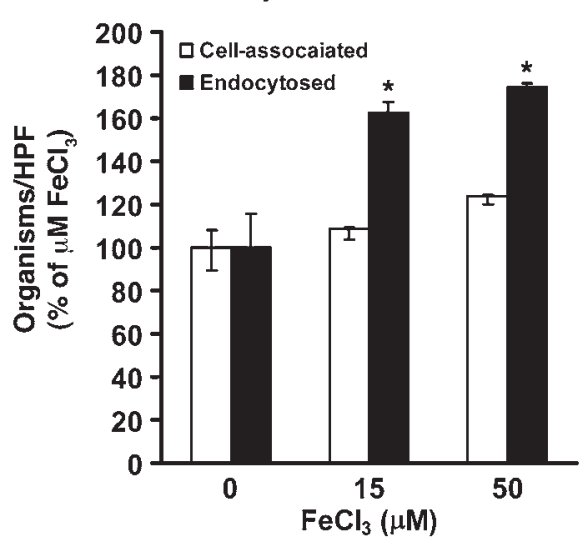

B

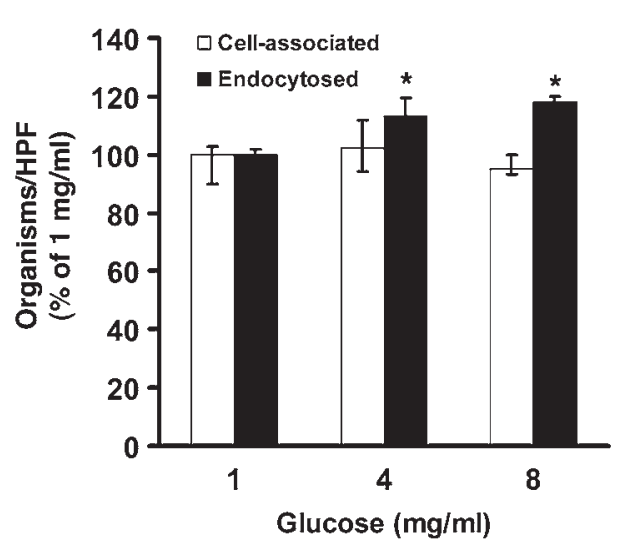

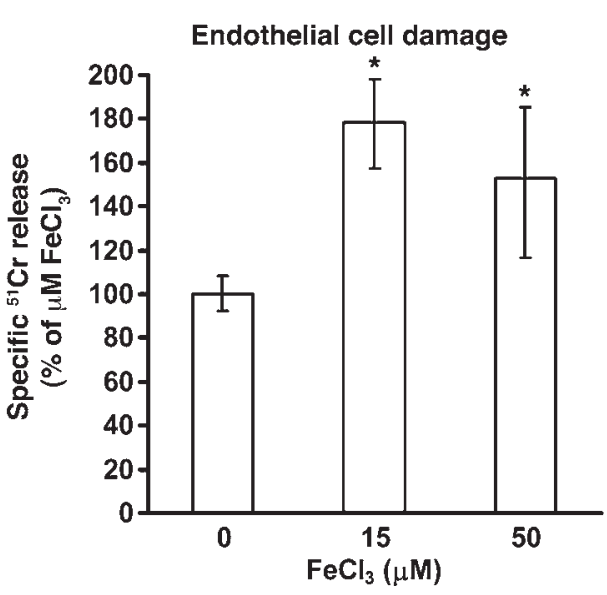

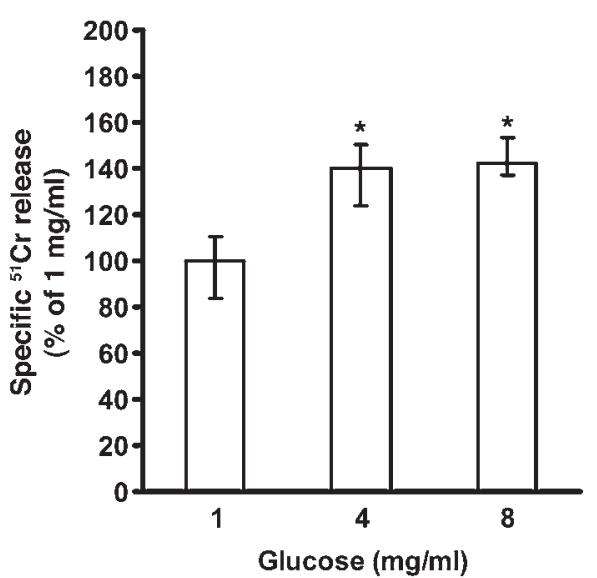

\section{Figure 8}

Iron and glucose concentrations consistent with those seen in DKA patients enhanced invasion of and subsequent damage to endothelial cells by $R$. oryzae. Endothelial cells exposed to high concentrations of iron (A) or glucose (B) were subsequently evaluated for their susceptibility to $R$. oryzae-mediated endocytose and damage. The endocytosis data were derived from more than 600 fungal cells interacting with approximately 200 endothelial cells/each group/ experiment, with an average of $51 \%$ and $58 \%$ endocytosis for no $\mathrm{FeCl}_{3}$ and $1 \mathrm{mg} / \mathrm{ml}$ glucose, respectively. ${ }^{*} P<0.01$ compared with no $\mathrm{FeCl}_{3}$ or with $1 \mathrm{mg} / \mathrm{ml}$ glucose by Wilcoxon rank-sum test. $n=6$ slides per group from 3 independent experiments for endocytosis, and $n=9$ wells per group from 3 independent experiments for damage assay. Data are expressed as median \pm interquartile range. stained with SYPRO Ruby (Molecular Probes, Invitrogen). The major band at approximately $75 \mathrm{kDa}$ was excised and microsequenced using MALDITOF MS/MS (Emory University Microchemical Facility).

To confirm the identity of GRP78, endothelial cell membrane proteins that bound to R. oryzae were separated on an SDS-polyacrylamide gel and transferred to PVDF-plus membranes. Membranes were probed with a rabbit anti-GRP78 Ab (Abcam), followed by HRP-conjugated goat antirabbit IgG (Pierce) as a secondary Ab. After incubation with SuperSignal West Dura Extended Duration Substrate (Pierce), the signals were detected using a CCD camera.

Colocalization of GRP78 with phagocytosed R. oryzae germlings by indirect immunofluorescence. We used a modification of our previously described method (31). Confluent endothelial cells on a $12-\mathrm{mm}$-diameter glass coverslip were infected with $10^{5} / \mathrm{ml}$ R. oryzae cells in RPMI 1640 medium that had been pregerminated for 1 or 3 hours. After 60 minutes incubation at $37^{\circ} \mathrm{C}$, the cells were gently washed twice with HBSS to remove unbound organisms and then fixed with $3 \%$ paraformaldehyde. After washing with 1\% BSA (Fisher) prepared in PBS-CM, the cells were incubated for 1 hour with rabbit anti-GRP78 Ab (Abcam), then counterstained with Alexa Fluor 488-labeled goat anti-rabbit IgG (Molecular Probes, Invitrogen). Cells were then permeabilized for 5 minutes in $0.5 \%$ Triton X-100 and incubated with Alexa Fluor 568-labeled phalloidin (Molecular Probes) for 1 hour to detect F-actin. After washing, the coverslip was mounted on a glass slide with a drop of ProLong Gold antifade reagent (Molecular Probes, Invitrogen) and viewed by confocal microscopy. The final confocal images were produced by combining optical sections taken through the $z$ axis.
Interactions of fungi with endothelial or $\mathrm{CHO}$ cells. The number of organisms endocytosed by endothelial cells or $\mathrm{CHO}$ cells was determined using a modification of our previously described differential fluorescence assay (14). Briefly, 12-mm glass coverslips in a 24-well cell culture plate were coated with fibronectin for at least 4 hours and seeded with endothelial or $\mathrm{CHO}$ cells until confluency. After washing twice with prewarmed HBSS, the cells were then infected with $10^{5}$ cells of $R$. oryzae in RPMI 1640 medium that had been germinated for 1 hour. Following incubation for 3 hours, the cells were fixed in $3 \%$ paraformaldehyde and were stained for 1 hour with $1 \%$ Uvitex (a gift from Jay Isharani, Ciba-Geigy, Greensboro, North Carolina, USA), which specifically binds to the chitin of the fungal cell wall. After washing 3 times with PBS, the coverslips were mounted on a glass slide with a drop of ProLong Gold antifade reagent and sealed with nail polish. The total number of cell-associated organisms (i.e., germlings adhering to monolayer) was determined by phase-contrast microscopy. The same field was examined by epifluorescence microscopy, and the number of uninternalized germlings (which were brightly fluorescent) was determined. The number of endocytosed organisms was calculated by subtracting the number of fluorescent organisms from the total number of visible organisms. At least 400 organisms were counted in 20-40 different fields on each slide. Two slides per arm were used for each experiment, and the experiment was performed in triplicate on different days.

R. oryzae-induced endothelial or $\mathrm{CHO}$ cell damage was quantified by using a chromium $\left({ }^{51} \mathrm{Cr}\right)$ release assay (36). Briefly, endothelial cells or $\mathrm{CHO}$ cells grown in 96-well tissue culture plates containing detachable wells were incubated with $1 \mu$ Ci per well of $\mathrm{Na}_{2}{ }^{51} \mathrm{CrO}_{4}(\mathrm{ICN})$ in M-199 medium (for endothelial cells) or Alpha minimum Eagle's medium (for $\mathrm{CHO}$ cells) for 16 hours. 


\section{A}

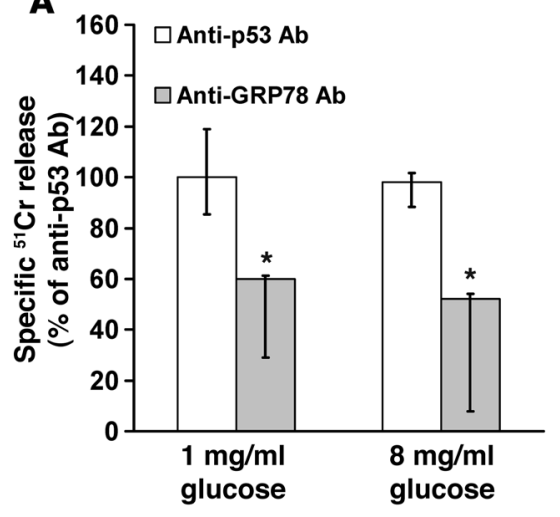

B

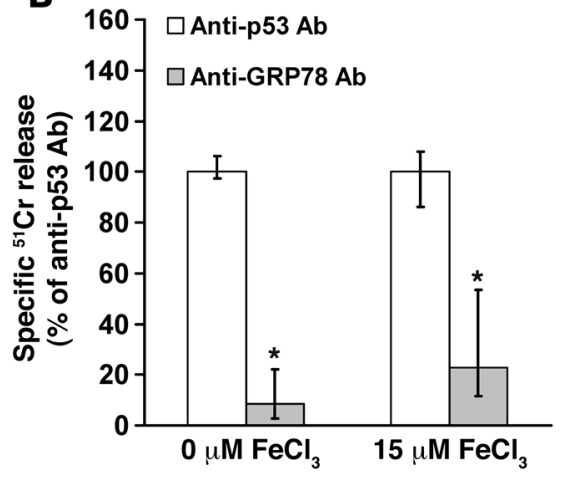

\section{Figure 9}

Anti-GRP78 mAb blocked endothelial cell endocytosis of $(\mathbf{A})$ and subsequent damage by (B) $R$. oryzae. Endothelial cells were incubated with $R$. oryzae in the presence of $50 \mu \mathrm{g}$ anti-GRP78 $\mathrm{Ab}$ or anti-p53 Ab (control). The endocytosis data were derived from more than 500 fungal cells interacting with approximately 150 endothelial cells/each group/experiment, with an average of $71 \%$ endocytosis in the control. ${ }^{*} P<0.02$ versus anti-p53 Ab. $n=6$ slides per group from 3 independent experiments for endocytosis, and $n=6$ wells per group from 2 independent experiments for damage assay. Data are expressed as median \pm interquartile range.
On the day of the experiment, the unincorporated ${ }^{51} \mathrm{Cr}$ was aspirated, and the wells were washed twice with warmed HBSS (Irvine Scientific). Cells were infected with fungal germlings $\left(1.5 \times 10^{5}\right.$ germinated for 1 hour $)$ suspended in $150 \mu \mathrm{l}$ RPMI 1640 medium (Irvine Scientific) supplemented with glutamine. Spontaneous ${ }^{51} \mathrm{Cr}$ release was determined by incubating endothelial or CHO cells in RPMI 1640 medium supplemented with glutamine without $R$. oryzae. After 3 hours of incubation at $37^{\circ} \mathrm{C}$ in a $5 \% \mathrm{CO}_{2}$ incubator, $50 \%$ of the medium was aspirated from each well and transferred to glass tubes, and the cells were manually detached and placed into another set of tubes. The amount of ${ }^{51} \mathrm{Cr}$ in the aspirate and the detached well was determined by gamma counting. The total amount of ${ }^{51} \mathrm{Cr}$ incorporated by endothelial cells in each well equaled the sum of radioactive counts per minute of the aspirated medium plus the radioactive counts of the corresponding detached wells. After the data were corrected for variations in the amount of tracer incorporated in each well, the percentage of specific endothelial cell release of ${ }^{51} \mathrm{Cr}$ was calculated by the following formula: $[($ experimental release $\times 2)-($ spontaneous release $\times 2)] /$ total incorporation - (spontaneous release $\times 2)$ ]. Each experimental condition was tested at least in triplicate and the experiment repeated at least once.

For Ab blocking of adherence, endocytosis, or damage caused by R. oryzde, the assays were carried out as above except that endothelial cells were incubating with $50 \mu \mathrm{g}$ anti-GRP78 or anti-p53 $\mathrm{Ab}$ (as an isotype matching control) (Santa Cruz Biotechnology Inc.) for 1 hour prior to addition of $R$. oryzae germlings. Similar experiments were carried out to determine the effect of anti-GRP78 Ab on A. fumigatus- and C. albicans-induced damage to endothelial cells, with the exception that the damage assay was carried out for 20 hours and 3 hours, respectively.

To determine the effects of chelating endothelial cell iron on interactions with $R$. oryzae, endothelial cells were incubated with different concentrations of phenanthroline for 16 hours. To prevent chelation of the radioisotope ${ }^{51} \mathrm{Cr}$ was added to endothelial cells 24 hours prior to the addition of phenanthroline (37). To confirm that the effects of phenanthroline on R. oryzae-induced endocytosis by and damage of endothelial cells were due to chelation of endothelial cell iron, exogenous iron in the form of hemin was added to endothelial cells at a final concentration of $20 \mu \mathrm{M}, 2$ hours before phenanthroline (37). As a positive control for prevention of endocytosis, the microfilament disruptant cytochalasin D (Sigma-Aldrich) was added at a concentration of $200 \mathrm{nM}$ simultaneously with $R$. oryzae germlings, and endocytosis was determined as above (14).

Transduction of endothelial cells with shRNA lentiviral particles. The shRNA lentiviral particles, including TurboGFP control (SHC003V), non-target control (SHC002V), and GRP78 target (TRCN01024) were purchased from Sigma-Aldrich. The non-target control contains a scrambled sequence (CAACAAGATGAAGAGCACCAA) not targeting any known human gene, while lentiviruses targeting the GRP78 gene contain sequence CTTGTTGGTGGCTCGACTCGA. The transductions were performed according to the manufacturer's protocol. Briefly, $1.6 \times 10^{4}$ endothelial cells were seeded into 96 -well plate and incubated for about 20 hours at $37^{\circ} \mathrm{C}$ in a $5 \% \mathrm{CO}_{2}$ incubator. Cells were infected with lentiviral particles at an MOI of 20 in the presence of $8 \mu \mathrm{g} / \mathrm{ml}$ polybrene (Sigma-Aldrich) overnight. The transduced cells were incubated in fresh M199 medium for 4 more days. Puromycin at $0.2 \mu \mathrm{g} / \mathrm{ml}$ was added to select for puromycin-resistant cell pools, which usually took approximately 10 days of incubating at $37^{\circ} \mathrm{C}$ in $5 \% \mathrm{CO}_{2}$. The puromycin-resistant cells were passaged until an appropriate amount of cells was obtained for endocytosis or damage assays as above. Reduction of GRP78 expression was confirmed by using real time RT-PCR (see below).

Quantification of GRP78 expression. For quantification of GRP78 expression in endothelial or CHO cells, real time RT-PCR was carried out using a Power SYBR Green Cells-to-CT kit (Applied Biosystems) to extract RNA from $2 \times 10^{4}$ cells. Primers to amplify GRP78 from endothelial cells and CHO cells were 5 '-GGAAAGAAGGTTACCCATGC- 3 ' and $5^{\prime}$-AGAAGAGACACATCGAAGGT-3'. Primers 5'-ACCATCTTCCAGGAGCGAG-3' and 5'-TAAGCAGTTGGTGGTGCAG-3' were used to amplify the housekeeping gene GAPDH, which was used as a control.

Effect of acidosis, iron, glucose, mannitol, and statins on R. oryzae-endothelial cell interactions. To study the effect of acidosis, endothelial cells exposed to different pHs, ranging from 6.8 to 7.4, were grown in MEM buffered with HEPES for 5 hours in the presence or absence of phenanthroline. Next, endothelial cells were washed twice with cold PBS, and GRP78 total expression was quantified by real-time RT-PCR. To study the effect of glucose and iron on endothelial cell GRP78 expression levels and subsequent interactions of endothelial cells with $R$. oryzae germlings, we incubated endothelial cells in MEM with varying $\mathrm{FeCl}_{3}$ or glucose concentrations for 5 hours or 20 hours, respectively (pilot studies demonstrated maximum enhancement of GRP78 expression at these time points). To study the effect of hyperosmolarity and statins on GRP78 expression, endothelial cells in MEM were incubated with 1, 4, or $8 \mathrm{mg} / \mathrm{ml} \mathrm{mannitol} \mathrm{or} \mathrm{5,} \mathrm{20,} \mathrm{or}$ $40 \mu \mathrm{g} / \mathrm{ml}$ lovastatin for 20 hours. MEM did not have any glutamate, since this acid was found to induce expression of GRP78 (38). GRP78 expression, endocytosis, and damage assays were conducted as above.

Cell surface expression of GRP78 on endothelial cells exposed to varying concentrations of $\mathrm{FeCl}_{3}$ was quantified using FACS analysis. Briefly, endothelial cells grown in 25 -cm flasks were dissociated using $1.5 \mathrm{ml}$ enzyme-free dissociation buffer (Invitrogen). Cells were blocked with 50\% goat serum, then stained with monoclonal anti-GRP78 Ab (BD Biosciences) at 1:100 for 1 hour. Endothelial cells were counterstained with Alexa Fluor 488-labeled anti-mouse IgG at 1:100 for 1 hour. Endothelial cells exposed 
A

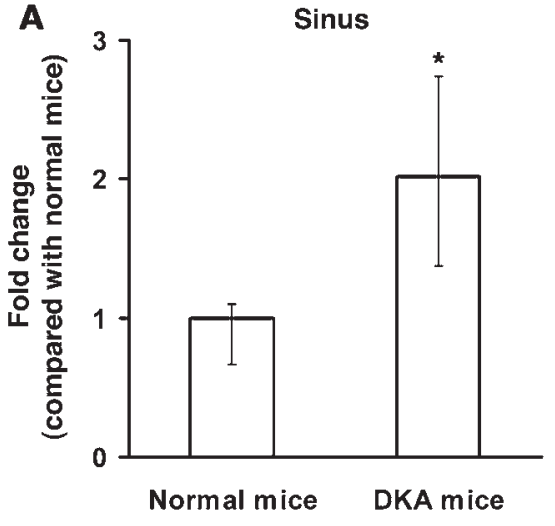

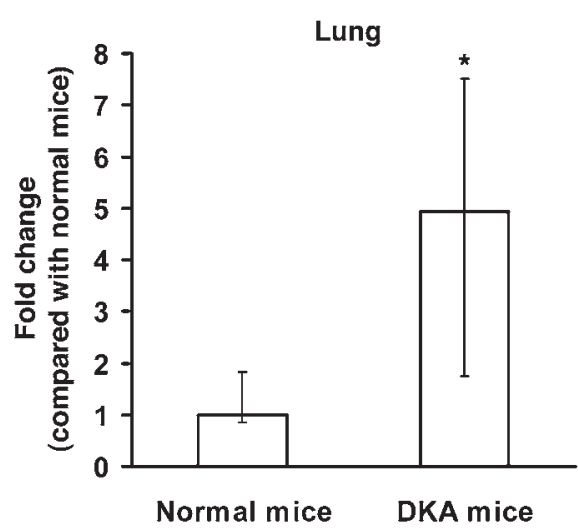

B

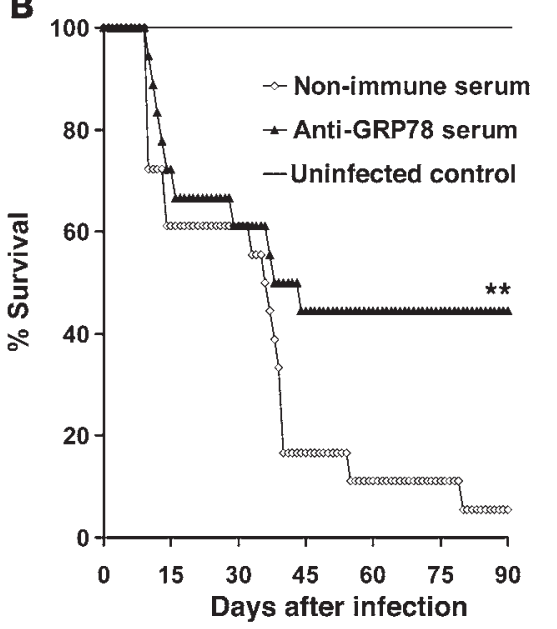

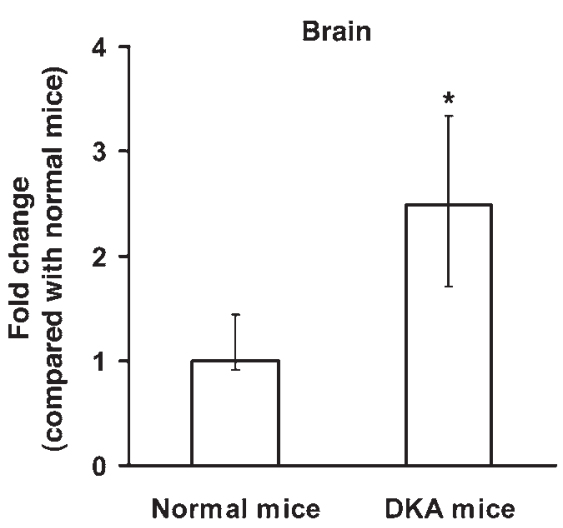

\section{Figure 10}

GRP78 is overexpressed in DKA mice and anti-GRP78 immune serum protects mice from mucormycosis. (A) Different organs harvested from DKA or normal mice ( $n=7$ per group) were processed for GRP78 quantification by real-time RT-PCR. ${ }^{*} P<0.05$ compared with normal mice. Data are expressed as median \pm interquartile range. (B) Survival of mice ( $n=18$ from 2 independent experiments with similar results) infected intranasally with $R$. oryzae ( $10^{5}$ spores actual inoculum) and treated with anti-GRP78 immune or non-immune sera. ${ }^{* *} P=0.037$ by log-rank test. The experiment was terminated on day 90 , with all remaining mice appearing healthy.

to a similar concentration of $\mathrm{FeCl}_{3}$ or glucose and stained with an isotype matching control IgG (BD Biosciences) were used as negative control. A FACSCaliber (BD) instrument equipped with an argon laser emitting at $488 \mathrm{~nm}$ was used for flow cytometric analysis. Fluorescence data were collected with logarithmic amplifiers. The population percent fluorescence of $5 \times 10^{3}$ events was calculated using CellQuest software (BD).

In vivo studies. For in vivo studies, DKA was induced in $\mathrm{BALB} / \mathrm{c}$ male mice $(\geq 20 \mathrm{~g})$ (National Cancer Institute) with a single i.p. injection of $190 \mathrm{mg} / \mathrm{kg}$ streptozotocin in $0.2 \mathrm{ml}$ citrate buffer 10 days prior to fungal challenge (17). Glycosuria and ketonuria were confirmed in all mice 7 days after streptozotocin treatment. To determine the available serum iron in DKA versus normal mice, serum samples were obtained from mice $(n=11)$ and the serum iron levels measured using the method of Artis et al. (11).

For quantification of GRP78 expression in mouse organs, lungs, brain, or sinus from normal or DKA mice were harvested 14 days following DKA induction (17). Organs were stored in RNAlater solution (Ambion). Approximately $25 \mathrm{mg}$ of brain or lung tissues was processed for RNA extraction using the RNAqueous-4PCR Kit (Ambion). Sinus bone was homogenized in liquid nitrogen (39), and RNA was extracted using the QIAGEN RNeasy Kit. For mouse GRP78 expression, primers 5'-TCTTGCCATTCAAGGTGGTTG-3' and 5'-TTCTTTCCCAAATACGCCTCAG-3' were used, while primers to amplify the housekeeping gene GAPDH were as above. Calculations and statistical analyses were carried out as described in ABI PRISM 7000 Sequence Detection System User Bulletin 2 (Applied Biosystems).

To generate immune serum for passive immunization, normal BALB/c mice were immunized by s.c. injection of $20 \mu \mathrm{g}$ recombinant hamster GRP78 (which is more than 98\% identical to murine or human GRP78) mixed with CFA (Sigma-Aldrich) or with CFA alone mixed with PBS to generate non-immune control serum $(40,41)$. Mice were boosted in incomplete Freund's adjuvant (IFA) 3 weeks later. Twelve days after the boost, serum was collected from GRP78-immunized or control mice (i.e., mice vaccinated with CFA/IFA without GRP78). Anti-GRP78 Ab titers were determined by using ELISA plates coated with $5 \mu \mathrm{g} / \mathrm{ml}$ of recombinant hamster GRP78 as we previously described (40). Immune or control sera $(0.25 \mathrm{ml})$ were administered i.p. to DKA recipient mice 2 hours before intranasal infection with $10^{5} R$. oryzae $99-880$ spores. Sera doses were repeated 3 days after infection, and survival of mice was followed for 90 days after infection. All procedures involving mice were approved by the Institutional Animal Use and Care Committee of the Los Angeles Biomedical Research Institute at Harbor-UCL Medical Center, according to the NIH guidelines for animal housing and care. 
Statistics. Differences in GRP78 expression and fungi-endothelial cell interactions were compared by the nonparametric Wilcoxon rank-sum test. The nonparametric log-rank test was used to determine differences in survival times. Comparisons with $P$ values less than 0.05 were considered significant.

\section{Acknowledgments}

This work was supported by Public Health Service grants R01 AI063503 and R21 AI082414-01 to A.S Ibrahim and M01 RR00425 for collecting human umbilical cord endothelial cells. A.S. Lee is supported by Public Health Service grant R01 CA027607, and S.G. Filler is supported by grant R01 AI054928. The authors gratefully acknowledge the technical assistance of Teclegiorgis Gebremariam and the perinatal nurses at the Harbor-UCLA General Clinical Research Center for collection of umbilical cords. The research described in this manuscript was conducted at the research facilities of the Los Angeles Biomedical Research Institute at Harbor-UCLA Medical Center.

Received for publication December 28, 2009, and accepted in revised form March 24, 2010.

Address correspondence to: Ashraf S. Ibrahim, Division of Infectious Diseases, Harbor-UCLA Medical Center, 1124 West Carson St., St. John's Cardiovascular Research Center, Torrance, California 90502, USA. Phone: 310.222.6424; Fax: 310.782.2016; E-mail: ibrahim@labiomed.org.

This work was presented in part at the Interscience Conference on Antimicorbial Agents and Chemotherapy in San Francisco, California, USA, on September 12-15, 2009 (abstract M-360).
1. Ibrahim AS, Edwards JE, Filler SG. Zygomycoses. In: Dismukes WE, Pappas PG, Sobel JD, eds. Clinical Mycology. New York, NY: Oxford University Press; 2003:241-251.

2. Spellberg B, Edwards J Jr, Ibrahim A. Novel perspectives on mucormycosis: pathophysiology, presentation, and management. Clin Microbiol Rev. 2005;18(3):556-569.

3. Gleissner B, Schilling A, Anagnostopolous I, Siehl I, Thiel E. Improved outcome of zygomycosis in patients with hematological diseases? Leuk Lymphoma. 2004;45(7):1351-1360.

4. Ibrahim AS, Spellberg B, Avanessian V, Fu Y, Edwards JE Jr. Rhizopus oryzae adheres to, is phagocytosed by, and damages endothelial cells in vitro. Infect Immun. 2005;73(2):778-783.

5. Isberg RR, Leong JM. Multiple beta 1 chain integrins are receptors for invasin, a protein that promotes bacterial penetration into mammalian cells. Cell. 1990;60(5):861-871.

6. Li J, Lee AS. Stress induction of GRP78/BiP and its role in cancer. Curr Mol Med. 2006;6(1):45-54.

7. Davidson DJ, et al. Kringle 5 of human plasminogen induces apoptosis of endothelial and tumor cells through surface-expressed glucose-regulated protein 78. Cancer Res. 2005;65(11):4663-4672.

8. Luo S, Mao C, Lee B, Lee AS. GRP78/BiP is required for cell proliferation and protecting the inner cell mass from apoptosis during early mouse embryonic development. Mol Cell Biol. 2006;26(15):5688-5697.

9. Reddy RK, Mao C, Baumeister P, Austin RC, Kaufman RJ, Lee AS. Endoplasmic reticulum chaperone protein GRP78 protects cells from apoptosis induced by topoisomerase inhibitors: role of ATP binding site in suppression of caspase-7 activation. J Biol Chem. 2003;278(23):20915-20924.

10. Morris JA, Dorner AJ, Edwards CA, Hendershot LM, Kaufman RJ. Immunoglobulin binding protein ( $\mathrm{BiP}$ ) function is required to protect cells from endoplasmic reticulum stress but is not required for the secretion of selective proteins. J Biol Chem. 1997;272(7):4327-4334.

11. Artis WM, Fountain JA, Delcher HK, Jones HE. A mechanism of susceptibility to mucormycosis in diabetic ketoacidosis: transferrin and iron availability. Diabetes. 1982;31(12):1109-1114.

12. Boelaert JR, et al. Mucormycosis during deferoxamine therapy is a siderophore-mediated infection. In vitro and in vivo animal studies. $J$ Clin Invest. 1993;91(5):1979-1986.

13. Ibrahim AS, et al. The iron chelator deferasirox protects mice from mucormycosis through iron starvation. J Clin Invest. 2007;117(9):2649-2657.

14. Ibrahim AS, Filler SG, Alcouloumre MS, Kozel TR, Edwards JE Jr. Ghannoum, MA. Adherence to and damage of endothelial cells by Cryptococcus neo- formans in vitro: role of the capsule. Infect Immun. 1995;63(11):4368-4374.

15. Kontoyiannis DP. Decrease in the number of reported cases of zygomycosis among patients with diabetes mellitus: a hypothesis. Clin Infect Dis. 2007;44(8):1089-1090.

16. Waldorf AR, Ruderman N, Diamond RD. Specific susceptibility to mucormycosis in murine diabetes and bronchoalveolar macrophage defense against Rhizopus. J Clin Invest. 1984;74(1):150-160.

17. Ibrahim AS, Avanessian V, Spellberg B, Edwards JE Jr. Liposomal amphotericin B, and not amphotericin B deoxycholate, improves survival of diabetic mice infected with Rhizopus oryzae. Antimicrob Agents Chemother. 2003;47(10):3343-3344.

18. Roden MM, et al. Epidemiology and outcome of zygomycosis: a review of 929 reported cases. Clin Infect Dis. 2005;41(5):634-653.

19. Ibrahim AS, Spellberg B, Edwards J Jr. Iron acquisition: a novel perspective on mucormycosis pathogenesis and treatment. Curr Opin Infect Dis. 2008;21(6):620-625.

20. Reed C, et al. Combination polyene-caspofungin treatment of rhino-orbital-cerebral mucormycosis. Clin Infect Dis. 2008;47(3):364-371.

21. Kar M, Chakraborti AS. Release of iron from haemoglobin - a possible source of free radicals in diabetes mellitus. Indian J Exp Biol. 1999;37(2):190-192.

22. van Campenhout A, van Campenhout CM, Lagrou AR, Manuel-y-Keenoy B. Transferrin modifications and lipid peroxidation: implications in diabetes mellitus. Free Radic Res. 2003;37(10):1069-1077.

23. Lee AS. GRP78 induction in cancer: therapeutic and prognostic implications. Cancer Res. 2007;67(8):3496-3499.

24. Ni M, Lee AS. ER chaperones in mammalian development and human diseases. FEBS Lett. 2007;581(19):3641-3651.

25. Kammoun HL, et al. GRP78 expression inhibits insulin and ER stress-induced SREBP-1c activation and reduces hepatic steatosis in mice. J Clin Invest. 2009;119(5):1201-1215.

26. Wang M, Wey S, Zhang Y, Ye R, Lee AS. Role of the unfolded protein response regulator GRP78/BiP in development, cancer and neurological disorders. Antioxid Redox Signal. 2009;11(9):2307-2316.

27. Misra UK, Gonzalez-Gronow M, Gawdi G, Wang F, Pizzo SV. A novel receptor function for the heat shock protein Grp78: silencing of Grp78 gene expression attenuates alpha $2 \mathrm{M} *$-induced signalling. Cell Signal. 2004;16(8):929-938.

28. Hardy B, Battler A, Weiss C, Kudasi O, Raiter A. Therapeutic angiogenesis of mouse hind limb ischemia by novel peptide activating GRP78 receptor on endothelial cells. Biochem Pharmacol. 2008;75(4):891-899.
29. Jindadamrongwech S, Thepparit C, Smith DR. Identification of GRP 78 (BiP) as a liver cell expressed receptor element for dengue virus serotype 2. Arch Virol. 2004;149(5):915-927.

30. Triantafilou K, Fradelizi D, Wilson K, Triantafilou M. GRP78, a coreceptor for coxsackievirus A9, interacts with major histocompatibility complex class I molecules which mediate virus internalization. J Virol. 2002;76(2):633-643.

31. Phan QT, Fratti RA, Prasadarao NV, Edwards JE Jr, Filler SG. N-cadherin mediates endocytosis of Candida albicans by endothelial cells. J Biol Chem. 2005;280(11):10455-10461.

32. Faye A, Ramey G, Foretz M, Vaulont S. Haptoglobin is degraded by iron in C57BL/ 6 mice: a possible link with endoplasmic reticulum stress. Blood Cells Mol Dis. 2007;39(3):229-237.

33. Lou LX, Geng B, Chen Y, Yu F, Zhao J, Tang CS. Endoplasmic reticulum stress involved in heart and liver injury in iron-loaded rats. Clin Exp Pharmacol Physiol. 2009;36(7):612-618.

34. Mote PL, Tillman JB, Spindler SR. Glucose regulation of GRP78 gene expression. Mech Ageing Dev. 1998;104(2):149-158.

35. Jaffe EA, Nachman RL, Becker CG, Minick CR Culture of human endothelial cells derived from umbilical veins. Identification by morphologic and immunologic criteria. J Clin Invest. 1973;52(11):2745-2756.

36. Ibrahim AS, et al. Bacterial endosymbiosis is widely present among zygomycetes but does not contribute to the pathogenesis of mucormycosis. J Infect Dis. 2008;198(7): 1083-1090.

37. Fratti RA, Belanger PH, Ghannoum MA, Edwards JE Jr, Filler SG. Endothelial cell injury caused by Candida albicans is dependent on iron. Infect Immun. 1998;66(1):191-196.

38. Yu Z, Luo H, Fu W, Mattson MP. The endoplasmic reticulum stress-responsive protein GRP78 protects neurons against excitotoxicity and apoptosis: suppression of oxidative stress and stabilization of calcium homeostasis. Exp Neurol. 1999;155(2):302-314.

39. Fu Y, et al. Cloning and functional characterization of the Rhizopus oryzae high affinity iron permease (rFTR1) gene. FEMS Microbiol Lett. 2004;235(1):169-176.

40. Ibrahim AS, Spellberg BJ, Avenissian V, Fu Y, Filler SG, Edwards JE Jr. Vaccination with recombinant $\mathrm{N}$-terminal domain of Als1 $\mathrm{p}$ improves survival during murine disseminated candidiasis by enhancing cell-mediated, not humoral, immunity. Infect Immun. 2005;73(2):999-1005.

41. Spellberg BJ, et al. Efficacy of the anti-Candida rAls $3 p-N$ or $\mathrm{rAls} 1 \mathrm{p}-\mathrm{N}$ vaccines against disseminated and mucosal candidiasis. J Infect Dis. 2006;194(2):256-260. 